\title{
Atraumatic Fractures of the Humerus Associated With Throwing Whilst Playing Dodgeball: A Case Series and Review of the Literature
}

\author{
Vincent Vinh Gia An, ${ }^{1,}$ Arnold Suzuki, ${ }^{2}$ John Trantalis, ${ }^{2}$ and Doron Sher ${ }^{2}$ \\ ${ }^{1}$ Sydney Medical School, University of Sydney, Sydney, Australia \\ ${ }^{2}$ Department of Orthopedic Surgery, Concord Repatriation General Hospital, Sydney, Australia \\ "Corresponding author: Vincent Vinh Gia An, Sydney Medical School, University of Sydney, Sydney, New South Wales, Australia. Tel: +61-405648186, E-mail: \\ vian2424@uni.sydney.edu.au \\ Received 2016 January 09; Revised 2016 March 29; Accepted 2016 April 23.
}

\begin{abstract}
Introduction: Five patients presented to the emergency department of a tertiary referral teaching hospital with atraumatic fractures of their humerus sustained during a recreational dodgeball tournament.

Case Presentation: The patients were young healthy individuals that described the fracture occurring during the act of throwing. Conclusions: The causes leading to fracture of the humerus during the act of a throw are discussed and the management strategies utilized.
\end{abstract}

Keywords: Humerus, Atraumatic Fracture, Dodgeball, Thrower's Fracture

\section{Introduction}

Fracture of a normal humerus, although rare, can occur during the act of throwing an object (1). Atraumatic "ball-thrower's" humeral shaft fractures have been associated with the act of throwing various objects including stone, cricket ball, baseball, softball, snowball, handball, shot put, javelins and hand grenades (1-12). The objective of dodgeball is to throw a ball and hit the opponent to remove them from the play area. There is no protective equipment associated with the sport.

The game of dodgeball is most commonly played with a $8.25 \mathrm{inch}(21 \mathrm{~cm})$ diameter rubber coated foam ball weighing 7.2 ounces (200 grams), but specifications across various leagues and tournaments worldwide range from a foam or air filled $7-10$ inches $(17.8-25.4 \mathrm{~cm})$ rubber or material coated ball (13-15). In comparison, stringent regulations govern the specifications of a major league baseball which weighs 5 - 5.25 ounces (142 - 149 grams) and is 2.8 - 3 inches $(7.3-7.6 \mathrm{~cm})$ in diameter $(16)$.

"Ball-thrower's" fractures are typically found in patients who are unskilled, healthy adults. To our knowledge, there is no case series in the literature describing this injury pattern related to the sport of dodgeball. Given recreational dodgeball is becoming an increasingly popular sport through many age groups, it is important to recognize this potential injury pattern.

This paper aims to present a series of five patients presenting to a tertiary referring teaching hospital following the same atraumatic mechanism of injury whilst playing dodgeball, and summarise the literature regarding this rare injury pattern. All patients described a full-effort throw and audible crack was heard following the release of the ball.

\section{Case Presentation}

The five patients presented to our institution with a mean age of 27.6 years (range: 26 - 31). All were male. At the point of injury all patients described the action of a "hard" throw, a sudden audible "crack", acute pain and deformity of the arm at the point of release of the ball. All patients denied any direct trauma to their arm. Three patients did not report the technique they utilized for the throw. The two that did recall described either a side arm or overhead throw respectively.

On X-ray, all patients had closed, extra-articular spiral distal-third fracture of the humerus with or without an associated medial butterfly fragment (Figure 1A and 2A). Two patients had an associated butterfly fragment. All injuries occurred with their dominant arm and there was no neurovascular compromise of the affected limb related to the fracture. No patient in this group had any relevant medical or surgical comorbidity. Metabolic bone disease was excluded in all patients as a predisposing factor through routine investigations at outpatient follow-up.

All patients were acutely managed conservatively with a hanging $U$ slab. Following consultation with consultant orthopedic surgeons (JT, DS), four patients received open reduction and internal fixation. All surgical cases were fixed using plate-screw osteosynthesis, specifically 
with the use of lag screw fixation and locking or dynamic compression plating (Figure $1 \mathrm{~B}$ and $\mathrm{C}$ ). There were no postoperative complications and all patients were discharged the day following their surgery.

The last patient received conservative management, with conversion from the hanging U Slab to the Sarmiento brace (Figure 2B). All fractures proceeded to union, and all patients regained full function of their arms at latest follow-up.

One patient presented on post-operative day $42 \mathrm{com}$ plaining of a "funny feeling", although on examination and radiologic investigation there were no abnormalities or hardware failure. This patient was managed conservatively with simple analgesia. At 1 year post-operatively, this patient presented again with a four-day history of right arm (the fractured and repaired arm) pain. Clinical and radiologic examination was again normal, and the patient was again managed with simple analgesia.

Another patient presented four months postoperatively complaining of pain and a "pop" making a pass with his fractured arm playing football. X-ray revealed an acute, oblique, mildly displaced fracture proximal to the cortical plate. This patient was managed conservatively with his arm placed in a sling and analgesia.

\section{Discussion}

This study presented a series of five atraumatic fractures of the humeral shaft occurring during a maximaleffort throwing action whilst playing dodgeball. Four of the patients were managed surgically, whilst the other was managed conservatively. All fractures proceeded to union. To our knowledge, this is the first study to present a series of fractures secondary to throwing whilst playing dodgeball.

Atraumatic fractures of the humerus secondary to throwing are a rare incidence, with only case reports and series detailing this particular mechanism of injury. "Ballthrower's" fractures typically occur in recreational baseball players attempting a hard throw, although these fractures have been identified in various other sports and activities (1-12). Concomitant radial nerve injury resulting in wrist drop occurs in up to $3-16 \%$ of patients (3-9), although all patients in our series were neurovascularly intact.

The overhand throwing kinetics in dodgeball have been likened to the kinetics in baseball pitchers (17). The act of throwing is a complex motion involving 6 main phases: wind-up, stride, arm-cocking, acceleration, followthrough and release (18). The action of opposing rotational forces from the proximal and distal ends of the humerus arm-cocking and acceleration phases of throwing result in torsional forces causing fracture (11).
A professional baseball pitcher has an average angular velocity of shoulder internal rotation of $6000 \mathrm{deg} / \mathrm{sec}$, and the elbow has an average angular velocity of $4600 \mathrm{deg} / \mathrm{sec}$ (11, 19-21). During the arm-cocking phase of the throwing action when the arm is in maximal external rotation the muscular forces at the proximal end of the humerus including subscapularis, pectoralis major, and latissimus dorsi muscles apply an internal rotational force to initiate the throw $(11,22,23)$. Prior to commencing the acceleration phase, the forearm, hand and object to be thrown create an external rotation inertial force upon the distal end of the humerus $(11,24)$. Therefore, there are opposing rotational forces applied to the humerus, namely internal rotational proximally and external rotation distally.

During the acceleration phase prior to ball release, antagonist muscle groups and the overall kinetic energy of the arm results in fracture (9). Some controversy in the literature exists regarding the precise muscle groups responsible at the time of humeral failure.

The location of the humerus fracture with our series of five patients was the consistent with previous reports in baseball pitchers who fractured at the junction of middle and distal thirds of the humerus $(9,11)$. The mean torque required to cause bony failure in cadaveric humeri is reported as $53+/-17 \mathrm{Nm}(25)$.

Between $92+\mid-16 \mathrm{Nm}$ and $90+\mid-20 \mathrm{Nm}$ of torque is produced during a full force throw by pitchers $(11,20)$. This was nearly double the torque required for bone failure (25). The maximum stressed part of the humerus during the throw was the distal third, which explains why the majority of thrower's injuries occur within the distal third of the humerus $(3,9)$.

"Ball thrower's" fractures seldom occur in players at the competitive or professional level $(11,26-28)$. Normal bone will remodel in response to the stresses as demonstrated by baseball pitchers humeri that have thicker and denser cortices $(11,29)$. Computed tomography analysis has found that lower thickness of the cortices was highly correlated with the likelihood of fracture. Therefore, thinner the cortex the less torsional stress it can withstand (30). Recreational players who have not had the opportunity for compensatory bony remodeling or skeletally immature patients may be more likely to sustain a spiral distal humerus fracture.

The history of prodromal symptoms prior to the onset of injury may indicate the development of a stress fracture in the humerus. This would allow the action of a throw in a recreational player to exceed the tolerances of torsion of the normal humerus and result in a complete fracture (11, 31). Three (50\%) of our cases reported an aching sensation associated with throwing prior to their injury, which may have been indicative of pre-existing stress fractures. Other 


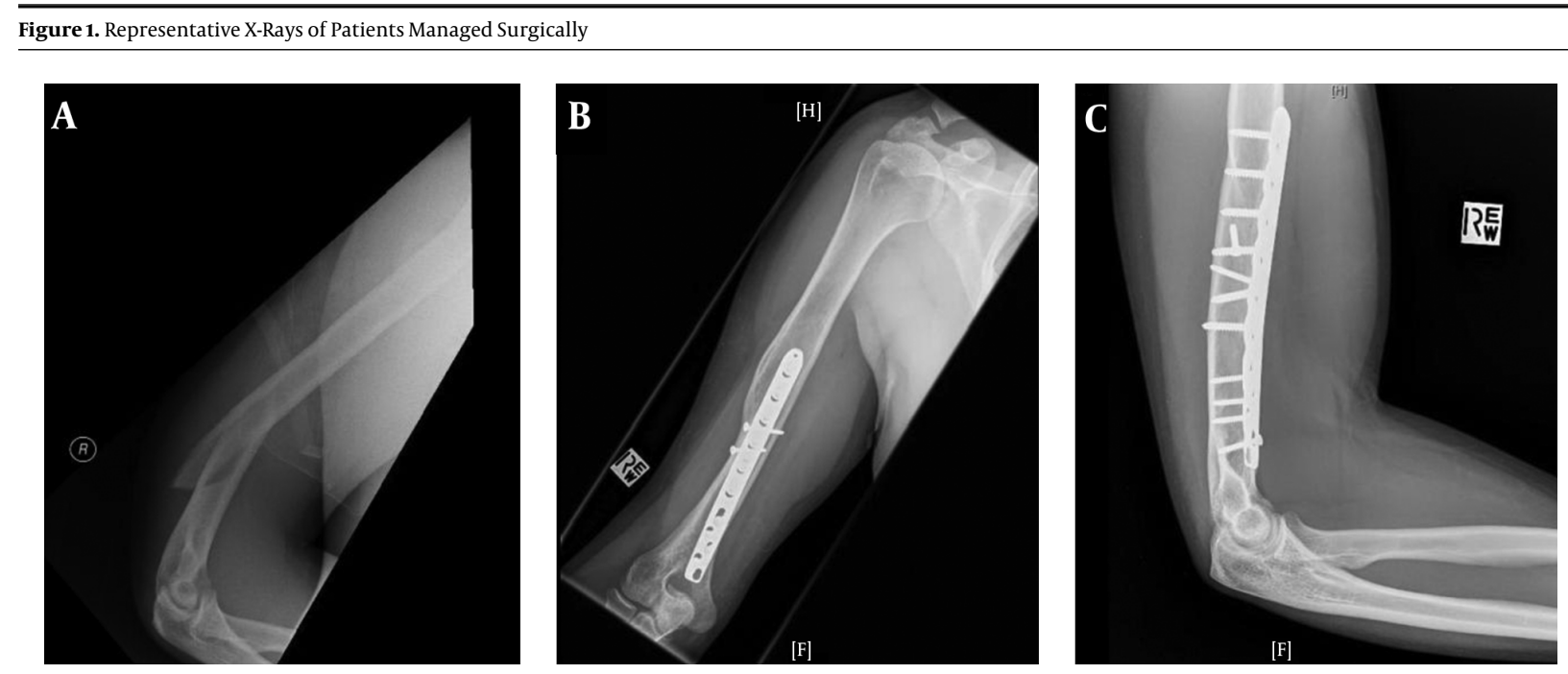

A, at presentation prior to treatment; B and C, 6 weeks following open reduction and internal fixation using 2 compression screws and a $5+6$ locking compression plate. Figure 2. Representative X-Rays of Patients Managed Conservatively
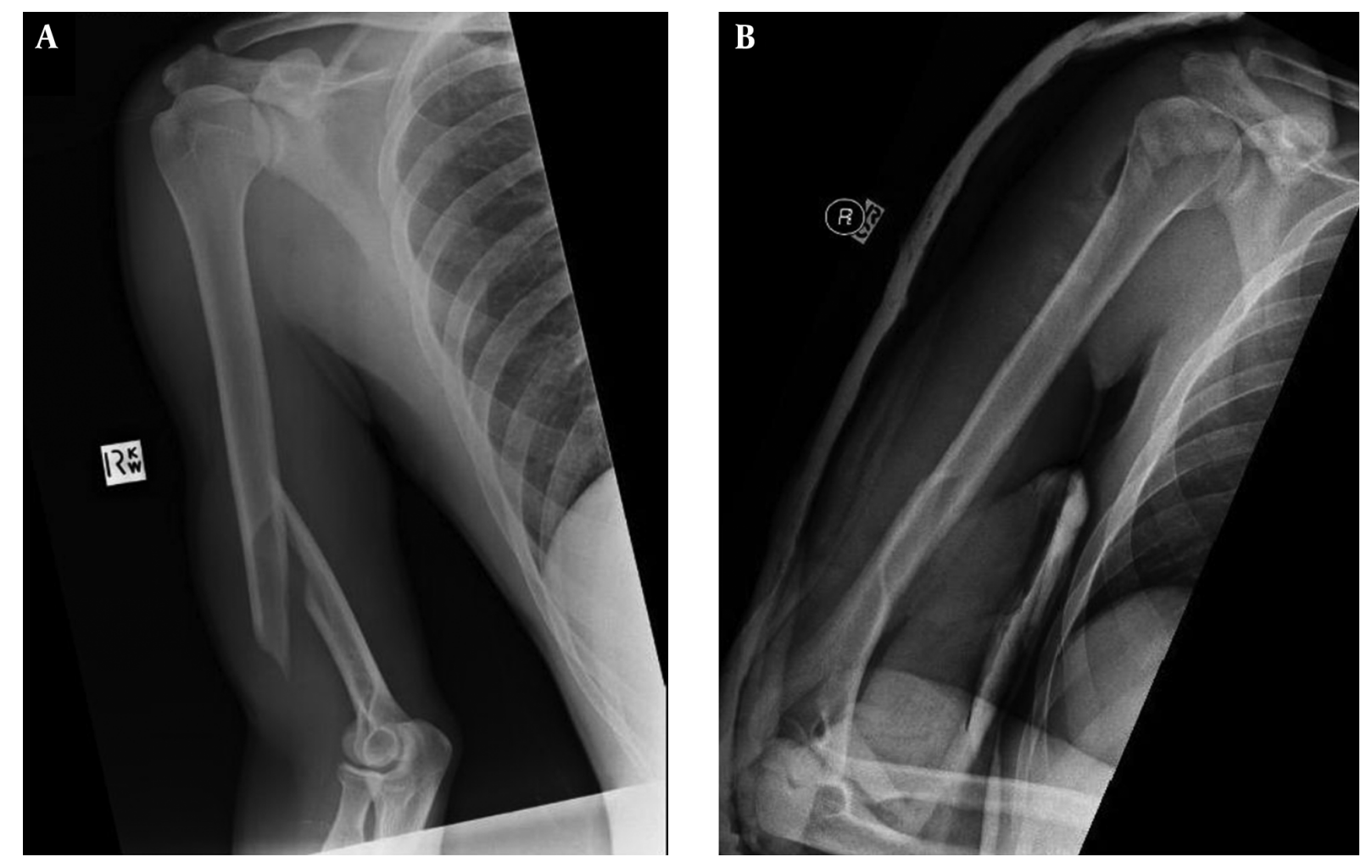

A, at presentation prior to treatment and B, after application of hanging U-Slab.

previously reported mechanisms contributing to fracture include muscle fatigue and poor throwing techniques (9, 32). Therefore, patients reporting these prodromal symp- toms could be considered at-risk of developing "throwers' fractures, and should be counselled appropriately.

The optimal management strategy for "throwers' frac- 
tures remains unclear. Several papers have cited nonsurgical management with a hanging cast with conversion to a functional brace as the gold standard of treatment, although it should be noted that these recommendations are made based on low-quality evidence (3, 9, 33). Surgical management via open reduction and internal fixation of the fracture demonstrates similar outcomes when compared to conservatively managed cases (9). A recent study by Kim et. al demonstrated favourable outcomes when using a locking plate system via an anterior humeral approach for distal thrower's spiral fractures of the humerus, demonstrating a slightly accelerated union time compared to previously reported times associated with bracing (17.3 weeks vs. 5 months) $(9,34)$. Future studies should investigate and compare conservative and surgical management strategies in the setting on 'throwers' fractures prospectively. Irrespective of management, all patients in our case series proceeded to union.

Overall, the reliability and validity of conclusions and statements made regarding "thrower's" fractures are limited by the low-quality of evidence, and the rarity of the injury pattern. Future cross-sectional studies using orthopedic registries could provide more reliable data in order to formulate a consistent, evidence-based approach to the prevention, management and rehabilitation of thrower's humeral fractures.

\subsection{Conclusion}

The popularity of dodgeball as a recreational sport is increasing and it is important to recognize that this is an injury that will likely present more frequently for orthopedic management. The management of the humerus fracture can be either non-operative through casting and functional bracing, or operative achieving similarly good results. Patient expectations need to be addressed through discussions of operative and non-operative management strategies. The exact mechanisms underpinning the torsional moment on the humerus resulting in bony failure remain unclear and require further biomechanical and prospective cross-sectional studies. A submission has been made to the Australian Dodgeball Federation outlining recommendations to screen potential "at risk" players with arm pain and advise them to avoid throwing activities and to seek medical clearance prior to participating in dodgeball.

\section{References}

1. Kuschner SH, Lane CS. Recurrent fracture of the humerus in a softball player. Am J Orthop (Belle Mead NJ). 1999;28(11):654-6. [PubMed: 10588474].

2. Bingham EL. Fractures of the humerus from muscular violence. $U S$ Armed Forces Med J. 1959;10(1):22-5. [PubMed: 13625441].
3. Chao SL, Miller M, Teng SW. A mechanism of spiral fracture of the humerus: a report of 129 cases following the throwing of hand grenades. J Trauma. 1971;11(7):602-5. [PubMed: 5555684].

4. Devas MB. Stress Fractures in Children.J Bone Joint Surg Br. 1963;45:52841. [PubMed: 14058330].

5. DiCicco JD, Mehlman CT, Urse JS. Fracture of the shaft of the humerus secondary to muscular violence. J Orthop Trauma. 1993;7(1):90-3. [PubMed: 8433208].

6. Evans PA, Farnell RD, Moalypour S, McKeever JA. Thrower's fracture: a comparison of two presentations of a rare fracture.J Accid Emerg Med. 1995;12(3):222-4. [PubMed: 8581257].

7. Gregersen HN. Fractures of the humerus from muscular violence. Acta Orthop Scand. 1971;42(6):506-12. [PubMed: 5144200].

8. Kaplan H, Kiral A, Kuskucu M, Arpacioglu MO, Sarioglu A, Rodop O. Report of eight cases of humeral fracture following the throwing of hand grenades. Arch Orthop Trauma Surg. 1998;117(1-2):50-2. [PubMed: 9457337].

9. Ogawa K, Yoshida A. Throwing fracture of the humeral shaft. An analysis of 90 patients. Am J Sports Med. 1998;26(2):242-6. [PubMed: 9548118].

10. Reed WJ, Mueller RW. Spiral fracture of the humerus in a ball thrower Am J Emerg Med. 1998;16(3):306-8. [PubMed: 9596440].

11. Sabick MB, Torry MR, Kim YK, Hawkins RJ. Humeral torque in professional baseball pitchers. Am J Sports Med. 2004;32(4):892-8. [PubMed: 15150034].

12. Santavirta S, Kiviluoto O. Transverse fracture of the humerus in a shotputter: a case report. Am J Sports Med. 1977;5(3):122-3. [PubMed: 860774].

13. NADA . Official Rules Chicago: National Amateur Dodgeball Association; 2007. [updated 2015]. Available from: http://www.dodgeballusa. com/rules.

14. IDA . Official dodgeball rules Vancouver: International Dodgeball Assocation; 2013. [updated 2015]. Available from: http://playdodgeball. org/official-dodgeball-rules.

15. NDL . US: National Dodgeball League; 2013. Available from: http:// thendl.com/theNDL-Dodgeball-101.asp.

16. MLB .US: Major League Baseball; 2013. Available from: http://mlb.mlb com/mlb/downloads/y2013/official_baseball_rules.pdf.

17. Wang Z, Sakurai S, Shimizu T. Kinetics Of Dodgeball Throwing With An Implication About Injury Mechanisms Of Elbow Joint. 1. Michigan: International Conference on Biomechanics in Sports; 2010.

18. Fleisig GS, Barrentine SW, Escamilla RF, Andrews JR. Biomechanics of overhand throwing with implications for injuries. Sports Med. 1996;21(6):421-37. [PubMed: 8784962].

19. Dillman CJ, Fleisig GS, Andrews JR. Biomechanics of pitching with emphasis upon shoulder kinematics. J Orthop Sports Phys Ther 1993;18(2):402-8. doi:10.2519/jospt.1993.18.2.402. [PubMed: 8364594].

20. Feltner M, Dapena J. Dynamics of the Shoulder and Elbow Joints of the Throwing Arm During a Baseball Pitch. J Appl Biomech. 1986;4(2):23559.

21. Pappas AM, Zawacki RM, Sullivan TJ. Biomechanics of baseball pitching. A preliminary report. Am J Sports Med. 1985;13(4):216-22. [PubMed 4025673].

22. Glousman R, Jobe F, Tibone J, Moynes D, Antonelli D, Perry J. Dynamic electromyographic analysis of the throwing shoulder with glenohumeral instability. J Bone Joint Surg Am. 1988;70(2):220-6. [PubMed: 3343266].

23. Gowan ID, Jobe FW, Tibone JE, Perry J, Moynes DR. A comparative electromyographic analysis of the shoulder during pitching. Professional versus amateur pitchers. Am J Sports Med. 1987;15(6):586-90. [PubMed: 3425786].

24. Werner SL, Fleisig GS, Dillman CJ, Andrews JR. Biomechanics of the elbow during baseball pitching.J Orthop Sports Phys Ther. 1993;17(6):2748. doi: 10.2519/jospt.1993.17.6.274. [PubMed: 8343786]. 
25. Schopfer A, Hearn TC, Malisano L, Powell JN, Kellam JF. Comparison of torsional strength of humeral intramedullary nailing: a cadaveric study. J Orthop Trauma. 1994;8(5):414-21. [PubMed: 7996325].

26. Hershman EB, Mailly T. Stress fractures. Clin Sports Med. 1990;9(1):183214. [PubMed: 2404618].

27. Sprenger TR. Fracture of humerus from muscular violence: case report. J Fla Med Assoc. 1985;72(2):101-3. [PubMed: 4056714]

28. Tullos HS, Erwin WD, Woods GW, Wukasch DC, Cooley DA, King JW. Unusual lesions of the pitching arm. Clin Orthop Relat Res. 1972;88:169-82. [PubMed: 5086567].

29. Jones HH, Priest JD, Hayes WC, Tichenor CC, Nagel DA. Humeral hypertrophy in response to exercise. J Bone Joint Surg Am. 1977;59(2):204-8. [PubMed: 845205].

30. Sakai K, Kiriyama Y, Kimura H, Nakamichi N, Nakamura T, Ikegami H, et al. Computer simulation of humeral shaft fracture in throwing.
Shoulder Elbow Surg. 2010;19(1):86-90. doi: 10.1016/j.jse.2009.05.006. [PubMed: 19574067].

31. Brukner P. Stress fractures of the upper limb. Sports Med. 1998;26(6):415-24. [PubMed: 9885097].

32. Peltokallio P, Peltokallio V, Vaalasti T. Fractures of the humerus from muscular voilence in sport. J Sports Med Phys Fitness. 1968;8(1):21-5. [PubMed: 5657942]

33. Colapinto MN, Schemitsch EH, Wu L. Ball-thrower's fracture of the humerus. CMAJ. 2006;175(1):31. doi: 10.1503/cmaj.060378. [PubMed: 16818904].

34. Kim SJ, Lee SH, Son H, Lee BG. Surgical result of plate osteosynthesis using a locking plate system through an anterior humeral approach for distal shaft fracture of the humerus that occurred during a throwing motion. Int Orthop. 2016;40(7):1489-94. doi: 10.1007/s00264-0152895-3. [PubMed: 26202018] 